\section{Cureus}

\title{
Assessment and Improvement of Quality of Life in Patients Undergoing Treatment for Head and Neck Cancer
}

Aamina Majid ${ }^{1}$, Bushra Z. Sayeed ${ }^{2}$, Maryam Khan ${ }^{3}$, Murk Lakhani ${ }^{4}$, Mariam M. Saleem ${ }^{2}$, Hina Rajani ${ }^{2}$, Priyanka Ramesh ${ }^{2}$, Nauman Hashmani ${ }^{5}$, Muneeba Zia ${ }^{2}$, Husnain Abid ${ }^{2}$, Bushra Majid ${ }^{1}$, Momal Jamali ${ }^{1}$, Kinza Murtaza ${ }^{2}$, Mujeeb-Ur-Rehman Shaikh ${ }^{6}$, Maryam Hussain $^{2}$

1. Internal Medicine, Dow University of Health Sciences, Karachi, PAK 2. Student, Dow University of Health Sciences (DUHS), Karachi, Pakistan 3. Miscellaneous, Dow University of Health Sciences, Karachi, PAK 4. Surgery, Dow University of Health Sciences (DUHS), Karachi, PAK 5. Ophthalmology, Hashmanis Hospital, Karachi, PAK 6. Student, Dow University of Health Sciences (DUHS), Karachi, Pakistan, Karachi, PAK

$\square$ Corresponding author: Nauman Hashmani, naumanhashmani@gmail.com Disclosures can be found in Additional Information at the end of the article

\section{Abstract}

Introduction: We compared the pre and post-treatment quality of life in head and neck cancer (HNC) patients and identified factors that could improve the quality of life in such patients.

Methods: The European Organization for Research and Treatment of Cancer Quality of Life Questionnaire C30 (EORTC QLQ-C30) questionnaire was administered to 84 patients' pre and post-treatment. Patients who had non-metastatic, measurable, and untreated HNCs were invited, provided that their age was below 80 years. We did not discriminate based on treatment modality, stage of cancer, or co-morbidities. Patients who were mentally incapacitated, with secondary or recurrent HNC, distant metastasis, skin cancer, congenital anomaly of the head and neck, chronic illness, or any previous or current psychiatric illness were excluded from the study. A high mean score on the functional scale and a low score on symptom scale signify a better quality of life. We used the dependent t-test to compare pre and post-treatment scores.

Results: We found no statistically significant differences in any variables, except the four symptom scales of diarrhoea, constipation, nausea/vomiting, and financial difficulty. All of these variables had increased mean scores with $\mathrm{p}$ values of $<0.001$. Also, we found no statistical significance $(p=0.250)$ when comparing the pre-treatment $(59.4 \pm 18.3)$ and posttreatment $(61.2 \pm 16.2)$ scores for the global health status.

Received 04/17/2017

Review began $04 / 24 / 2017$ Review ended 04/26/2017 Published 05/02/2017

\section{(c) Copyright 2017}

Majid et al. This is an open access article distributed under the terms of the Creative Commons Attribution License CC-BY 3.0., which permits unrestricted use, distribution, and reproduction in any medium, provided the original author and source are credited.
Conclusion: We found no improvement in the quality of life in HNC patients despite intervention. In fact, diarrhoea, constipation, nausea/vomiting, and financial difficulty of these patients worsened post-treatment.

Categories: Otolaryngology, General Surgery, Oncology

Keywords: oncology, head and neck cancer, quality of life

\section{Introduction}

Cancer is a leading cause of death worldwide after heart diseases [1]. Head and neck cancer 
(HNC), an umbrella term for malignancies of larynx and hypopharynx, nasal cavity, paranasal sinuses, nasopharynx, oropharynx, oral cavity, and salivary gland, accounts for about half a million cases annually, ranking it as the sixth most common cancer globally [2]. About 90\% of HNCs are squamous cell carcinomas (HNSCC) arising from the epithelium in the region of head and neck after exposure to carcinogens, such as tobacco, smoking, and alcohol [3]. In developing countries like Pakistan, carcinoma of the oral mucosa is the most commonly diagnosed HNSCC with males having a greater preponderance, attributed to the local custom of excessive use of cigarettes, tobacco, betel nut, and areca nut. Due to advancements in diagnostic and treatment modalities, the survivorship of HNC patients has increased significantly during the last decade [1]. However, these remarkable but aggressive treatment methods also bring along numerous side effects that significantly affect the quality of life (QoL) of the patients.

QoL, also known as the patient's perception of his/her general well-being, is a multidimensional concept that includes psychological, social, occupational, functional, and physical well-being [4]. The term health-related QoL (HRQoL) is preferred over QoL as it only focuses on the health status and disease-related issues, such as symptoms and functions [5]. Due to the anatomic complexity and functional importance of the head and neck region, patients of HNC face multiple challenges pre and post-treatment, such as dysphagia, pain, xerostomia, dietary restrictions, and physical restrictions besides disfigurement and problems in sexual life $[4,6]$. Therefore, apart from survivorship, the assessment of HRQol has become imperative for optimum patient-centred decision-making.

Assessment of the HRQoL of HNC patients and its relationship with various demographic and disease variables remains a neglected area of research in Pakistan [7-8], and thus, less emphasis has been laid upon improving the QoL and returning the patient to his pre-illness functional state. Therefore, the primary objectives of this study were to measure the HRQoL and to evaluate factors that could improve the QoL of HNC patients undergoing treatment. Besides this, the secondary objective was to exclusively highlight the impact on separate domains of HRQoL, an important survival outcome that can guide healthcare professionals to tailor treatment and rehabilitation according to expected functional outcomes.

\section{Materials And Methods}

A prospective cohort study was conducted at the Civil Hospital Karachi (CHK) after approval from the Institutional Review Board of Dow University Health Sciences. The study was carried out during the period of January 1, 2016 to June 30, 2016.

Although HNC is more common among males [9], we decided to select both males and females for our study. A total of 84 patients with non-metastatic, measurable, and untreated cancer of the oral cavity were invited consecutively to participate in this QoL study, with patients' age being less than 80 years of age. The patients were selected irrespective of whether they were receiving either radiotherapy, chemotherapy, or a combination of both as the treatment modality with curative intent. We recruited the patients regardless of the stage of cancer they were suffering from and the comorbidities that they already had. Patients who were mentally incapacitated, with secondary or recurrent HNC, distant metastasis, skin cancer, congenital anomaly of the head and neck, chronic illness, or any previous or current psychiatric illness were excluded from the study. Those who were unable to answer the questionnaire due to senile dementia or severe intercurrent disease were also excluded.

Both written and verbal consent were taken from the patients before interviewing them. The patients were requested to come to CHK where they were asked to fill out the questionnaire by trained interviewers before (baseline) and between three to six months after undergoing the treatment. Two trained interviewers conducted the interviews in order to eliminate any chances 
of interviewer bias. The interviewers were well versed with the major languages of Pakistan, namely English, Urdu, Sindhi, and Pushto, to remove any language barrier between the interviewer and the patient and to ensure that all eligible patients were included.

The QoL of patients was evaluated by means of the European Organization for Research and Treatment of Cancer Quality of Life Questionnaire C30 (EORTC QLQ-C30) [10]. The multicultural validity and psychometric scales established on the basis of this questionnaire are considered satisfactory [10-13]. With the assistance of the EORTC QLQ-C30, 17 scales were extracted from the first 30 items. These scales included five functional scales (strenuous physical activity, mild physical activity, emotional involvement, cognitive functioning, and social interaction), three symptom scales (lethargy, nausea and vomiting, and pain), six singleitem symptom scales (dyspnoea, insomnia, decreased appetite, constipation, diarrhoea, and financial problems), a scale for depression and amnesia, and one global health status/QoL scale. Greater scores in functioning and global health status/QoL are indicative of a higher level of functioning and a better Q0L, respectively, whereas higher scores in the symptom scale amount to a higher level of symptomatology and a poor QoL.

Data was entered and analysed using the Statistical Package for the Social Sciences (SPSS) v23.0 (IBM SPSS Statistics, Armonk, NY). For categorical variables, frequencies and percentages were reported while for continuous variables, mean and standard deviation were reported.

Comparison of continuous variables was done using dependent T-test.

\section{Results}

\section{General characteristics}

A total of 84 patients were included in the study with the majority being male $(\mathrm{n}=76 ; 90.5 \%)$. More than two-thirds were married $(\mathrm{n}=65 ; 77.4 \%)$, had a low income $(\mathrm{n}=73 ; 86.9 \%)$, and had received primary/secondary education $(n=61 ; 72.6 \%)$. The most prevalent primary tumour site was the oral cavity $(n=54 ; 64.3 \%)$ and nearly three-fifths of the total patients received chemotherapy and radiotherapy combined $(n=51 ; 60.7 \%)$. Around one-third of the patients were diagnosed as Stage IV $(n=32 ; 38.1 \%)$. A great majority were smokers, followed by betel nut chewers and alcohol consumers ( $\mathrm{n}=79,94.0 \% ; \mathrm{n}=72,85.7 \% ; \mathrm{n}=53,63.1 \%$, respectively). More than one-third of the patients suffered from diabetes as well $(\mathrm{n}=37 ; 44.0 \%)$. The general and demographic characteristics of the patients are summarized in Table 1. 


\section{Cureus}

\section{Patient Characteristics}

Sex

Male

Female

Age, years

$\leq 60$

$>60$

Marital Status

Married

Unmarried

Income

Low-income

Level of education

Primary/Secondary

Treatment Modality

Chemotherapy + Radiation

Stage of cancer

$$
\text { Stage IV }
$$

Site of cancer

$$
\text { Oral cavity }
$$

Smokers

Betel nut chewers

Alcohol consumers

Co-morbidities

Diabetics
Percent (\%)

90.5

9.5

77.4

94

85.7

63.1

44

TABLE 1: The Baseline Characteristics of the Patients 


\section{Cureus}

We found no statistical significance $(\mathrm{p}=0.250)$ when comparing the pre-treatment $(59.4 \pm 18.3)$ and post-treatment $(61.2 \pm 16.2)$ scores for the global health status. Similarly, no significance was found in any of the pre-treatment and post-treatment functional scales: Physical (83.2 \pm 14.5 to $84.1 \pm 13.9, \mathrm{p}=0.341)$, emotional $(67.4 \pm 19.7$ to $68.1 \pm 20.3, \mathrm{p}=0.410)$, social $(81.3 \pm 19.9$ to $77.3 \pm 19.2, p=0.907)$, role $(73.8 \pm 20.2$ to $72.6 \pm 20.7, p=0.648)$, and cognitive $(90.5 \pm 16.3$ to $90.2 \pm 15.9, \mathrm{p}=0.548)$.

After completion of treatment, a statistically significant increment in the complaints of diarrhoea (1.6 to 6.8), constipation (1.4 to 6.4), and nausea/vomiting (8 to 12.3) was observed (p values $=<0.001)$. There was also a slight increase in the mean scores of fatigue, dyspnoea, and loss of appetite after treatment. An improvement was only seen in insomnia $(p=0.995)$ and pain ( $p=0.959)$; however, none of these reached statistical significance. Financial difficulty increased after treatment (43.6 to 58.2) and was statistically significant ( $\mathrm{p}=<0.001)$. Table 2 presents the mean scores and standard deviations of various scales and single items. 


\section{Cureus}

\begin{tabular}{|c|c|c|c|c|c|}
\hline \multirow{2}{*}{ Scales and Items } & \multicolumn{2}{|c|}{ Pre-treatment } & \multicolumn{2}{|c|}{ Post-treatment } & \multirow{2}{*}{$\mathbf{P}$} \\
\hline & Mean & $\mathrm{SD}^{*}$ & Mean & $S D^{*}$ & \\
\hline Global Quality of Life & 59.4 & 18.3 & 61.2 & 16.2 & 0.25 \\
\hline \multicolumn{6}{|l|}{ Functional Scales } \\
\hline Physical & 83.2 & 14.5 & 84.1 & 13.9 & 0.341 \\
\hline Emotional & 67.4 & 19.7 & 68.1 & 20.3 & 0.41 \\
\hline Social & 81.3 & 19.9 & 77.3 & 19.2 & 0.907 \\
\hline Role & 73.8 & 20.2 & 72.6 & 20.7 & 0.648 \\
\hline Cognitive & 90.5 & 16.3 & 90.2 & 15.9 & 0.548 \\
\hline \multicolumn{6}{|l|}{ Symptom Scales } \\
\hline Fatigue & 27.3 & 15.4 & 29.7 & 13.6 & 0.143 \\
\hline Pain & 29 & 19.2 & 24.2 & 16.3 & 0.959 \\
\hline Dyspnoea & 9.1 & 17.1 & 9.7 & 18 & 0.412 \\
\hline Insomnia & 37.6 & 20.3 & 30 & 17.2 & 0.995 \\
\hline Loss of appetite & 26.2 & 13.4 & 29.1 & 14.2 & 0.087 \\
\hline Diarrhoea & 1.6 & 6.2 & 6.8 & 9.8 & $<0.001$ \\
\hline Constipation & 1.4 & 4.2 & 6.4 & 7.3 & $<0.001$ \\
\hline Nausea/vomiting & 8 & 6.4 & 12.3 & 7.1 & $<0.001$ \\
\hline Financial difficulty & 43.6 & 20.1 & 58.2 & 23.2 & $<0.001$ \\
\hline
\end{tabular}

\section{TABLE 2: Scores of EORTC QLQ C30 Among HNC Patients Pre and Post-treatment}

EORTC QLQ C30: European Organization for Research and Treatment of Cancer Quality of Life Questionnaire C30; HNC: head and neck cancer; SD: Standard deviation

\section{Discussion}

Our results suggest that there was no statistically significant change in the HRQoL of our patients as assessed prior to the treatment and post-treatment. A literature review shows variable results regarding the HRQoL of HNC patients. Some studies reported that HRQoL returns to the pre-treatment score while others showed a decline or increase in the score [1416]. Most of our patients had concurrent chemoradiation therapy (CCRT) as it has a better survival rate for locally advanced stages as compared to radiotherapy alone [17-18]. Therefore, the modality of the treatment cannot be the reason for the insignificant change in HRQoL in this study.

We found a significant male preponderance (90\%), with the majority being under 60 years of 
age and of low socioeconomic status. Most of them were smokers, betel nut chewers, or alcoholics, which may have a strong correlation with the predominant existence of oral cavity cancer in our study. These demographic characteristics of the observed populace are in correspondence with the known risk factors of HNC [19-21].

Our study also shows an increased incidence in those belonging to low socioeconomic status, which might be a major reason for emotional instability and, hence, resulting in increased psychological stress. This suggests that psychological stress is a key factor leading to the consumption of tobacco, betel nut, or alcohol [22]. Moreover, our data shows that the majority of our patients are literate; however, literacy does not necessarily equate to awareness [23]. Therefore, there is a dire need to spread this knowledge about the preventable/avoidable risk factors of the HNC.

No statistically significant improvement was seen in the global quality of life, functional scale, and symptom scale, but there is observable variation in the individual components. There was some improvement in the physical and emotional function while the other three variables decreased post-treatment, including role performance, cognitive, and social function. It is likely due to post-treatment supportive care factors. A feeding tube after the treatment can be associated with low role performance and social function [24], for example. Contrary to our results, however, the literature review expressed an increase in mental health after treatment because of depression and anxiety due to the cancer diagnosis before the treatment [24-25].

A major factor for the negative outcome of this study was the presentation of the patient at an advanced stage of the disease. In order to address this issue, patients and healthcare providers need to work hand in hand. A vast majority of patients neglect oral lesions due to its silent presentation, lack of education, lack of resources, or misdiagnosis. Therefore, it is vital for healthcare providers to focus on screening the high-risk population for pre-malignant features and arrange health awareness programs regarding risk factors, prevalence, and early presenting features of HNC. Also, it is important to counsel cancer patients regarding treatment modalities, support facilities, and follow-up plans for improvement in physical as well as psychological QoL.

Most of the HNC patients in our study were habitual betel nut chewers (85.7\%). Studies suggest that HNC patients with betel nut chewing as a risk factor express different mutations than those who were not addicted to betel nuts [26-27]. Consequently, these patients respond to treatment modality in a separate manner [27-28]. Therefore, further evaluation should be considered to assess and compare the effect of individual treatment modalities in relation to causative agents of the cancer.

There are a few limitations in this study which need to be considered. Firstly, this study was administered using a validated questionnaire EORTC QLQ C30. However, it would have yielded more specific information if we would have employed an additional cancer site-specific EORTC QoL module of head and neck cancer (QLQ-H\&N43 questionnaire). Secondly a longer followup time period would have broadened our horizon of understanding even more.

\section{Conclusions}

This study emphasizes that HNC patients' HRQoL can express similar scores before and after the treatment. As for significant changes post-treatment, we observed worsening in the frequency of diarrhoea, nausea/vomiting, constipation, and financial difficulty. For future studies, efficacy can be improved by considering the long-term follow-up assessment and treatment modality according to causative agents affecting the HRQoL in these patients. 


\section{Additional Information \\ Disclosures}

Human subjects: Consent was obtained by all participants in this study. Dow University of Health Sciences issued approval. Animal subjects: All authors have confirmed that this study did not involve animal subjects or tissue. Conflicts of interest: In compliance with the ICMJE uniform disclosure form, all authors declare the following: Payment/services info: All authors have declared that no financial support was received from any organization for the submitted work. Financial relationships: All authors have declared that they have no financial relationships at present or within the previous three years with any organizations that might have an interest in the submitted work. Other relationships: All authors have declared that there are no other relationships or activities that could appear to have influenced the submitted work.

\section{References}

1. Siegel RL, Miller KD, Jemal A: Cancer statistics, 2016. CA Cancer J Clin. 2016, 66:7-30. 10.3322/caac. 21332

2. Tshering Vogel DW, Thoeny HC: Cross-sectional imaging in cancers of the head and neck: how we review and report. Cancer Imaging. 2016, 16:20. 10.1186/s40644-016-0075-3

3. Argiris A, Karamouzis MV, Raben D, Ferris RL: Head and neck cancer. Lancet. 2008, 371:1695709. 10.1016/S0140-6736(08)60728-X

4. Murphy BA, Ridner S, Wells N, Dietrich M: Quality of life research in head and neck cancer: a review of the current state of the science. Crit Rev Oncol Hematol. 2007, 62:251-67. 10.1016/j.critrevonc.2006.07.005

5. Doward LC, McKenna, SP: Defining patient-reported outcomes. Value Health. 2004, 7:S4-8. 10.1111/j.1524-4733.2004.7s102.x

6. D'Souza PJ, Chakrabarty J, Sulochana B, Gonsalves J: Quality of life of head and neck cancer patients receiving cancer specific treatments. JKIMSU. 2013, 2:51-57.

7. Bhurgri Y, Bhurgri A, Usman A, Pervez S, Kayani N, Bashir I, Ahmed R, Hasan SH: Epidemiological review of head and neck cancers in Karachi . Asian Pac J Cancer Prev. 2006, 7:195-200.

8. Zaidi SM, Manzoor NF, Akhtar S: The challenge of head \& neck squamous cell carcinoma control in Pakistan. J Pak Med Assoc. 2010, 60:703-4.

9. Siegel RL, Miller KD, Jemal A: Cancer Statistics, 2017. CA Cancer J Clin. 2017, 67:7-30. $10.3322 /$ caac. 21387

10. EORTC QLQ-C30 Scoring Manual. (2001). Accessed: May 1, 2017: http://www.eortc.be/qol/files/SCManualQLQ-C30.pdf.

11. Aaronson NK, Ahmedzai S, Bergman B, Bullinger M, Cull A, Duez NJ, Filiberti A, Flechtner H, Fleishman SB, de Haes JC, Kaasa S, Klee M, Osoba D, Razavi D, Rofe PB, Schraub S, Sneeuw K, Sullivan M, Takeda F: The European Organization for Research and Treatment of Cancer QLQ-C30: a quality-of-life instrument for use in international clinical trials in oncology. J Natl Cancer Inst. 1993, 85:365-76. 10.1093/jnci/85.5.365

12. Osoba D, Zee B, Pater J, Warr D, Kaizer L, Latreille J: Psychometric properties and responsiveness of the EORTC Quality of Life Questionnaire (QLQ-C30) in patients with breast, ovarian and lung cancer. Qual Life Res. 1994, 3:353-64. 10.1007/BF00451727

13. Hjermstad MJ, Fossa SD, Bjordal K, Kaasa S: Test/retest study of the European Organization for Research and Treatment of Cancer Core Quality-of-Life Questionnaire. J Clin Oncol. 1995, 13:1249-54. 10.1200/JCO.1995.13.5.1249

14. Hammerlid E, Silander E, Hörnestam L, Sullivan M: Health-related quality of life three years after diagnosis of head and neck cancer--a longitudinal study. Head Neck. 2001, 23:113-25. 10.1002/1097-0347(200102)23:2<113::AID-HED1006>3.0.CO;2-W

15. Rogers SN, Lowe D, Brown JS, Vaughan ED: The University of Washington head and neck cancer measure as a predictor of outcome following primary surgery for oral cancer. Head Neck. 1999, 21:394-401. 10.1002/(SICI)1097-0347(199908)21:5<394::AID-HED3>3.0.CO;2-Q

16. Abendstein H, Nordgren M, Boysen M, Jannert M, Silander E, Ahlner-Elmqvist M, Hammerlid 
E, Bjordal K: Quality of life and head and neck cancer: a 5 year prospective study . Laryngoscope. 2005, 115:2183-92.

17. Machtay M, Moughan J, Trotti A, Garden AS, Weber RS, Cooper JS, Forastiere A, Ang KK: Factors associated with severe late toxicity after concurrent chemoradiation for locally advanced head and neck cancer: an RTOG analysis. J Clin Oncol. 2008, 26:3582-89. 10.1200/JCO.2007.14.8841

18. List MA, Siston A, Haraf D, Schumm P, Kies M, Stenson K, Vokes EE: Quality of life and performance in advanced head and neck cancer patients on concomitant chemoradiotherapy: a prospective examination. J Clin Oncol. 1999, 17:1020-28.

10.1097/01.MLG.0000181507.69620.14

19. Head and Neck Cancers. (2017). Accessed: April 1, 2017: http://www.cancer.gov/types/headand-neck/head-neck-fact-sheet.

20. Onakoya PA, Nwaorgu OG, Adenipekun AO, Aluko AA, Ibekwe TS: Quality of life in patients with head and neck cancers. J Natl Med Assoc. 2006, 98:765-70.

21. de Melo Filho MR, Rocha BA, Pires MB, Fonseca ES, Freitas EM, Martelli Junior H, Santos FB: Quality of life of patients with head and neck cancer (Article in English, Portuguese) . Braz J Otorhinolaryngol. 2013, 79:82-88. 10.5935/1808-8694.20130014

22. Sorensen G, Barbeau E, Hunt MK, Emmons K: Reducing social disparities in tobacco use: a social-contextual model for reducing tobacco use among blue-collar workers. Am J Public Health. 2004, 94:230-39. 10.2105/AJPH.94.2.230

23. Almutairi KM, Alonazi WB, Alodhayani A, Vinluan JM, Ahmad M, Alhurishi SA, Alsadhan N, Alsalem MM, Alotaibi NE, Alaqeel AM: A cross-sectional assessment of literacy and awareness, attitudes, and beliefs about colorectal cancer and its screening in Riyadh Region. J Cancer Educ. 2016, Epub ahead of print. 10.1007/s13187-016-1129-8

24. Ronis DL, Duffy SA, Fowler KE, Khan MJ, Terrell JE: Changes in quality of life over 1 year in patients with head and neck cancer. Arch Otolaryngol Head Neck Surg. 2008, 134:241-48. 10.1001/archoto.2007.43

25. de Graeff A, de Leeuw JR, Ros WJ, Hordijk GJ, Blijham GH, Winnubst JA: Long-term quality of life of patients with head and neck cancer. Laryngoscope. 2000, 110:98-106.

10.1097/00005537-200001000-00018

26. Hsieh CH, Chang JW, Hsieh JJ, Hsu T, Huang SF, Liao CT, Wang HM: Epidermal growth factor receptor mutations in patients with oral cavity cancer in a betel nut chewing-prevalent area. Head Neck. 2011, 33:1758-64. 10.1002/hed.21665

27. Chiu TJ, Chen CH, Chien CY, Li SH, Tsai HT, Chen YJ: High ERCC1 expression predicts cisplatin-based chemotherapy resistance and poor outcome in unresectable squamous cell carcinoma of head and neck in a betel-chewing area. J Transl Med. 2011, 9:31. 10.1186/14795876-9-31

28. Chang PM, Hsieh YY, Chen MH, Tzeng CH, Chu PY, Chang SY, Chen PM, Yang MH: Cetuximab-based therapy in recurrent/metastatic head and neck squamous cell carcinoma: experience from an area in which betel nut chewing is popular. J Chin Med Assoc. 2010, 73:292-99. 10.1016/S1726-4901(10)70064-2 